\title{
Geographical variations of risk factors associated with HCV infection in drug users in southwestern China
}

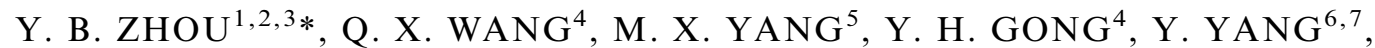 \\ S. J. NIE ${ }^{1,2,3}$, S. LIANG ${ }^{7,8}$, L. NAN ${ }^{4}$, A. COATSWORTH ${ }^{9}$, A. H. YANG ${ }^{1,2,3}$, \\ Q. $\mathrm{LIAO}^{4}, \mathrm{X} . \mathrm{X} . \mathrm{SONG}^{1,2,3}$ AND Q.W. JIANG ${ }^{1,2,3 *}$ \\ ${ }^{1}$ Department of Epidemiology, School of Public Health, Fudan University, Shanghai, China; ${ }^{2}$ Key Laboratory of \\ Public Health Safety, Ministry of Education (Fudan University), Shanghai, China; ${ }^{3}$ Tropical Disease Research \\ Center, Fudan University, Shanghai, China; ${ }^{4}$ Center for Disease Prevention and Control of Liangshan Prefecture, \\ Sichuan, China; ${ }^{5}$ Xuhui Center for Disease Prevention and Control, Shanghai, China; ${ }^{6}$ Department of \\ Biostatistics, University of Florida, Gainesville, FL, USA; ${ }^{7}$ Emerging Pathogens Institute, University of Florida, \\ Gainesville, FL, USA; 8 Department of Environmental and Global Health, College of Public Health and Health \\ Professions, University of Florida, Gainesville, FL, USA; ${ }^{9}$ Department of Epidemiology, College of Public Health \\ and Health Professions, University of Florida, Gainesville, FL, USA
}

Received 4 August 2015; Final revision 2 October 2015; Accepted 7 October 2015;

first published online 6 November 2015

\section{SUMMARY}

Hepatitis $\mathrm{C}$ virus (HCV) has become a global public health problem. Many studies have been conducted to identify risk factors for HCV infection. However, some of these studies reported inconsistent results. Using data collected from 11 methadone clinics, we fit both a non-spatial logistical regression and a geographically weighted logistic regression to analyse the association between HCV infection and some factors at the individual level. This study enrolled 5401 patients with $30 \cdot 0 \% \mathrm{HCV}$ infection prevalence. The non-spatial logistical regression found that injection history, drug rehabilitation history and senior high-school education or above were related to HCV infection; and being married was negatively associated with $\mathrm{HCV}$ infection. Using the spatial model, we found that Yi ethnicity was negatively related to $\mathrm{HCV}$ infection in $62.0 \%$ of townships, and being married was negatively associated with $\mathrm{HCV}$ infection in $81.0 \%$ of townships. Senior high-school education or above was positively associated with HCV infection in $55 \cdot 2 \%$ of townships of the Yi Autonomous Prefecture. The spatial model offers better understanding of the geographical variations of the risk factors associated with $\mathrm{HCV}$ infection. The geographical variations may be useful for customizing intervention strategies for local regions for more efficient allocation of limited resources to control transmission of HCV.

Key words: Drug users, geographically weighted logistic regression, geographical variation, hepatitis C virus.

\section{INTRODUCTION}

Hepatitis C virus (HCV) has become a leading cause of chronic hepatitis, cirrhosis and hepatocellular carcinoma $[1,2]$ with an estimated 170 million people infected worldwide. It is estimated that 26.4 million people are infected in China alone, representing

\footnotetext{
* Author for correspondence: Dr Y. B. Zhou, Department of Epidemiology, School of Public Health, Fudan University, 138 Yi Xue Yuan Road, Shanghai, China.

(Email: z_yibiao@hotmail.com) [Y.B.Z.]

(Email: jiangqw@fudan.edu.cn) [Q.W.J.]
} 
$\sim 2 \cdot 2 \%$ (range $0 \cdot 52-3 \cdot 15$ ) of the general population [3]. Deaths related to $\mathrm{HCV}$ exceeded deaths related to HIV in the United States [1]. HCV is hyperendemic in injection drug users (IDUs), and the prevalence can be as high as $90 \%$ in this population [3, 4]. A meta-analysis showed that the pooled prevalence of $\mathrm{HCV}$ infection in IDUs was $61.4 \%$ [95\% confidence interval (CI) 55.7-67.2, max 98.7] in China, and its prevalence showed marked geographical variation [3]. There have been many studies that have examined the associations between socioeconomic, demographic and drug-related behavioural factors and $\mathrm{HCV}$ infection in drug users; however, some of these results are contradictory [3, 5]. For example, one meta-analysis showed that IDUs sharing needles/ syringes had a greater risk of being infected with $\mathrm{HCV}$ than non-sharing IDUs [5]. However, another meta-analysis indicated that no significant difference was found in the risk of $\mathrm{HCV}$ infection between needle-sharing and non-needle-sharing IDUs [3]. Some studies suggested that level of education was independently associated with $\mathrm{HCV}$ infection $[6,7]$; however, other studies showed no such association $[8,9]$. These inconsistent findings might be the consequence of spatial heterogeneity in the effects or clusters of some risk factors or be related to other potential reasons including the conflicting results from different target populations. Our previous research suggested there was significant global and local geographical autocorrelation in HCV infections [10]. The spatial autocorrelation, if not accounted for, may result in bias in the estimates and incorrect standard errors [11]. Currently, most studies have used nonspatial regression techniques to analyse risk factors of $\mathrm{HCV}$ infection making the assumption that the association is stationary across space. Few studies have used spatial regression methods to explore risk factors of $\mathrm{HCV}$ infection at the individual level assuming the relationship is non-stationary across space. Therefore, using geographically weighted logistic regression (GWLR), we aim to account for and describe the local variation in the relationship between demographic, socioeconomic and drug-use behavioural characteristics and $\mathrm{HCV}$ infection in drug users in an Yi Autonomous Prefecture, Sichuan province, China. This may provide new insights about who is at risk for $\mathrm{HCV}$ infection and where. Thus, our analysis is potentially useful for tailoring prevention and healthcare programmes to the needs of diverse groups and for ensuring accessibility of health services to those most in need.

\section{METHODS}

\section{Study area and population}

The Yi Autonomous Prefecture, located in the southwest of China, is on one of the main drug-trafficking routes from the 'Golden Triangle' to northwest and central China. It is one of the largest illicit drug production and distribution centres of China. A population of 4.9 million people live in this prefecture composed of 16 counties and a city and 618 townships. Approximately $50 \%$ of the population belongs to the Yi ethnic group. HIV/AIDS has been endemic in this region since the first HIV case was identified in drug users in 1995. Since late 2012, ten regular methadone clinics and one mobile methadone clinic have been established, the first of which was established in 2004. All patients attending the 11 clinics from 2004 to 2012 were selected as the study population, and detailed information on the infrastructure and procedures of these clinics and the patients has been reported elsewhere [10, 12-16]. All these patients were tested for $\mathrm{HCV}$ infection 1 month after first entry into the clinic. Meanwhile, all these drug users were asked to take part in a questionnaire investigation. The questionnaires were administered face-to-face in a private room by a same-sex interviewer who was trained in administration of questionnaires. The information on residency of drug users was collected from their identification card.

\section{Data collection and measurement}

Data regarding HCV infection, demographic and socioeconomic factors, drug-use behaviours and residency of all subjects treated in the 11 national clinics during the period 2004-2012 were collected from the national methadone database [5, 14]. Our outcome variable was $\mathrm{HCV}$ infection.

Our independent variables cover three domains of interest. The first domain was drug-use behaviours which include injection, sharing syringes and drug rehabilitation. The second involves demographic factors including gender, age, ethnicity, and marital status. Gender is a dummy variable with female as the reference group. Age was divided into four age groups $(<30,30-39,40-49, \geqslant 50$ years $)$ where the $<30$ years group serves as the reference group, and three dummy variables are created. Ethnicity is classified as $\mathrm{Yi}$, Han (reference group) and other using two dummy variables. Marital status was categorized into single (reference), married, divorced and 
Geographical variations of risk factors

Table 1. The characteristics and prevalence of HCV infection of the national methadone clients in southwest China

\begin{tabular}{|c|c|c|c|c|}
\hline Study variable & No. of clients examined & Infection prevalence $(\%)$ & $\chi^{2}$ & $P$ \\
\hline \multicolumn{5}{|l|}{ Drug-use behaviours } \\
\hline \multicolumn{5}{|l|}{ History of injection drug use } \\
\hline Yes & 2407 & $46 \cdot 2$ & \multirow{2}{*}{$545 \cdot 8$} & \multirow{2}{*}{$<0 \cdot 00$} \\
\hline No & 2994 & $16 \cdot 9$ & & \\
\hline \multicolumn{5}{|l|}{ History of sharing syringes } \\
\hline Yes & 909 & $42 \cdot 8$ & \multirow[t]{2}{*}{$85 \cdot 3$} & \multirow[t]{2}{*}{$<0 \cdot 00$} \\
\hline No & 4492 & $27 \cdot 4$ & & \\
\hline \multicolumn{5}{|l|}{ History of drug rehabilitation } \\
\hline Yes & 2523 & $42 \cdot 6$ & \multirow[t]{2}{*}{$358 \cdot 8$} & \multirow[t]{2}{*}{$<0 \cdot 00$} \\
\hline No & 2878 & $18 \cdot 9$ & & \\
\hline \multicolumn{5}{|l|}{ Demographic factors } \\
\hline Gender & & & & \\
\hline Males & 4583 & $30 \cdot 0$ & \multirow[t]{2}{*}{$0 \cdot 0$} & \multirow[t]{2}{*}{$0 \cdot 911$} \\
\hline Females & 818 & $29 \cdot 8$ & & \\
\hline \multicolumn{5}{|l|}{ Age, years } \\
\hline$<30$ & 2369 & $30 \cdot 2$ & \multirow[t]{4}{*}{$12 \cdot 2$} & \multirow[t]{4}{*}{0.007} \\
\hline $30-39$ & 2323 & $31 \cdot 3$ & & \\
\hline $40-49$ & 633 & $25 \cdot 8$ & & \\
\hline$\geqslant 50$ & 76 & $18 \cdot 4$ & & \\
\hline \multicolumn{5}{|l|}{ Marital status } \\
\hline Single & 1156 & $42 \cdot 4$ & \multirow[t]{4}{*}{$145 \cdot 1$} & \multirow[t]{4}{*}{$<0.001$} \\
\hline Married & 3998 & $25 \cdot 6$ & & \\
\hline Divorced & 185 & $45 \cdot 4$ & & \\
\hline Widowed & 62 & $38 \cdot 7$ & & \\
\hline \multicolumn{5}{|l|}{ Ethnicity } \\
\hline Yi & 4364 & $26 \cdot 1$ & \multirow[t]{3}{*}{$166 \cdot 1$} & \multirow[t]{3}{*}{$<0 \cdot 00$} \\
\hline Han & 994 & $46 \cdot 5$ & & \\
\hline Other & 43 & $46 \cdot 5$ & & \\
\hline \multicolumn{5}{|l|}{ Socioeconomic factors } \\
\hline \multicolumn{5}{|l|}{ Employment } \\
\hline Farming & 4192 & $25 \cdot 9$ & \multirow[t]{4}{*}{$185 \cdot 2$} & \multirow[t]{4}{*}{$<0 \cdot 001$} \\
\hline Service sector & 187 & $42 \cdot 2$ & & \\
\hline Unemployed & 800 & $49 \cdot 0$ & & \\
\hline Other & 222 & $29 \cdot 3$ & & \\
\hline \multicolumn{5}{|l|}{ Educational attainment } \\
\hline No school & 1196 & $25 \cdot 3$ & $66 \cdot 7$ & $<0 \cdot 00$ \\
\hline Primary school & 2417 & $27 \cdot 2$ & & \\
\hline Junior high school & 1257 & $38 \cdot 3$ & & \\
\hline Senior high school or above & 531 & 33.9 & & \\
\hline
\end{tabular}

widowed. The third domain focuses on socioeconomic factors, including occupation and education. Occupation was classified into farmer, service sector, unemployed, and other (reference) such as factory worker, government employee, etc. Educational achievement was divided into four levels (three dummy variables): no school (reference group), elementary school, junior high school and senior high school or above. Our independent variables also include 'methadone clinic' which was divided into 11 levels.

In order to explore the local associations between $\mathrm{HCV}$ infection and risk factors (as mentioned above) at the individual level, the location of each individual was defined as the geographical coordinate (i.e. latitude/longitude) of the centre of the township in which he/she resided; township is the smallest geographical unit in the present analysis.

\section{Statistical analysis}

Non-spatial logistical regression

Using SPSS software (SPSS Inc., USA), the prevalence of infection and characteristics of the patients in the methadone clinics were analysed, and 
multivariable non-spatial logistical regression was employed to analyse the association between HCV infection and risk factors and interactions between variables.

\section{GWLR}

A GWLR model was used to analyse the local associations between $\mathrm{HCV}$ infection and risk factors adjusting for spatial autocorrelation. The model is figured by [17]:

$\log \left(\frac{P\left(y_{i}=1\right)}{1-P\left(y_{i}=1\right)}\right)=\beta_{0}\left(u_{i}, v_{i}\right)+\sum_{j=1}^{k} \beta_{j}\left(u_{i}, v_{i}\right) x_{i j}$

where $y_{i}$ and $x_{i j}$, denote the HCV infection status and explanatory variables for individual $i$ with location coordinates $\left(u_{i}, v_{i}\right)$, and $\beta_{0}\left(u_{i}, v_{i}\right)$ and $\beta_{j}\left(u_{i}, v_{i}\right)$ are the location-specific intercept and coefficients.

The GWLR model was implemented with GWR 4.0 software (https://geodacenter.asu.edu/software/ downloads/gwr_downloads). The kernel function used for geographical weighting to estimate local coefficients is 'adaptive bi-square'. The bandwidth is the number of nearest neighbours to be included in the bi-square kernel. The 'golden section search' method was used to automatically determine the best bandwidth size based on Akaike's Information Criterion (AIC) corrected for small sample size bias, where the bandwidth with the lowest AIC was used in the final analysis. Geographical variability for each coefficient can be assessed by comparing the AICs between the GWLR model and the global logistic regression model assuming invariant model coefficients [17]. The coefficient of an independent variable in the model represents the change in log odds of the response given a unit change in that variable. Taking the exponentiation of the coefficient yields the odd ratio (OR) corresponding to a unit change in the variable. The local estimates (OR) and $P$ values are visualized in maps to demonstrate the geographical variations in the association between HCV infection and individual factors. The results are relatively insensitive to the choice of kernel functions (e.g. bi-square and Gaussian) for geographically weighted regression [17]. All variables were entered first into the GWLR regression model, then the variable with the largest $P$ value was removed from the model until only the variables with some local $P$ values $<0 \cdot 1$ remained within the GWLR model.

\section{RESULTS}

\section{Prevalence of HCV infection}

A total of 5401 patients with complete information regarding risk factors, home address, name of methadone clinic attended and results of their $\mathrm{HCV}$ test were obtained from the national database. These patients came from 405 of the 618 townships of the $\mathrm{Yi}$ Autonomous Prefecture. The prevalence of $\mathrm{HCV}$ infection in the population was $30.0 \%(1620 / 5401)$. Table 1 presents the infection prevalence of $\mathrm{HCV}$ in different characteristics of the national methadone clients. Clients with a history of IDU, or of sharing syringes or of drug rehabilitation had a higher prevalence of HCV infection than those without such a history. Patients who were married, of Yi ethnicity, employed in farming or had no schooling had a lower prevalence of $\mathrm{HCV}$ infection than those who were not (Table 1). Additionally, $44.6 \%$ of the patients had injection history, and 16.8\% (909/5401) shared syringes (Table 1).

\section{Univariable and multivariable non-spatial logistical regressions}

For the univariable non-spatial logistic regression, other factors were associated significantly with $\mathrm{HCV}$ infection except for gender (Table 2).

For multivariable non-spatial regression, both IDU and drug rehabilitation were significantly $(P<0.001)$ positively associated with $\mathrm{HCV}$ infection [adjusted OR (aOR) 3.04, 95\% CI 2.65-3.48; aOR 1·76, 95\% CI $1 \cdot 53-2 \cdot 03$, respectively] in drug-use behaviours (Table 2). Compared to others, both unemployed and service-sector work were significantly $(P<0 \cdot 01)$ related to $\mathrm{HCV}$ infection (aOR 1.20, 95\% CI 1.33-1.91; aOR $1 \cdot 73,95 \%$ CI 1.25-2.39, respectively) (Table 2$)$. Being married was significantly $(P<0.001)$ negatively associated with $\mathrm{HCV}$ infection (aOR $0 \cdot 70$, $95 \%$ CI $0 \cdot 61-0 \cdot 81)$ compared to being single. Having senior high-school education or above was significantly $(P=0.039)$ positively related to $\mathrm{HCV}$ infection (aOR 1.28, 95\% CI (1.03-1.59) compared to no school (Table 2).

\section{Multivariable spatial logistical regression}

The optimal bandwidth size was 170 (individuals) in this study. The value of AIC in the global regression was $5894 \cdot 0$, whereas $\mathrm{AIC}=5707 \cdot 2$ for GWLR. Table 3 presents the factors which were significantly and locally associated with $\mathrm{HCV}$ infection. For a 
Table 2. The association of HCV infection and risk factors from univariable and multivariable non-spatial logistical regressions

\begin{tabular}{|c|c|c|c|c|c|c|}
\hline \multirow[b]{2}{*}{ Study variable } & \multicolumn{3}{|c|}{ Univariable regression } & \multicolumn{3}{|c|}{ Multivariable regression } \\
\hline & OR & $95 \% \mathrm{CI}$ & $P$ value & $\mathrm{aOR}$ & $95 \% \mathrm{CI}$ & $P$ value \\
\hline Constant & - & - & - & $0 \cdot 22$ & - & $<0 \cdot 001$ \\
\hline \multicolumn{7}{|l|}{ Drug-use behaviours } \\
\hline Injection history $(1=$ yes, $0=$ no $)$ & $4 \cdot 22$ & $3 \cdot 73-4 \cdot 78$ & $<0 \cdot 001$ & 3.04 & $2 \cdot 65-3 \cdot 48$ & $<0 \cdot 001$ \\
\hline Drug rehabilitation history $(1=$ yes, $0=$ no $)$ & $3 \cdot 18$ & $2 \cdot 81-3 \cdot 59$ & $<0 \cdot 001$ & $1 \cdot 76$ & $1 \cdot 53-2 \cdot 03$ & $<0 \cdot 001$ \\
\hline Sharing syringes $(1=$ yes, $0=$ no $)$ & 1.98 & $1 \cdot 71-2 \cdot 30$ & $<0 \cdot 001$ & - & - & - \\
\hline \multicolumn{7}{|l|}{ Demographic factors } \\
\hline \multicolumn{7}{|l|}{ Gender (ref. $=$ female $)$} \\
\hline Male $(1=$ yes, $0=$ no $)$ & $1 \cdot 01$ & $0 \cdot 86-1 \cdot 19$ & $0 \cdot 911$ & - & - & - \\
\hline \multicolumn{7}{|l|}{ Marital status (ref. $=$ single) } \\
\hline Married $(1=$ yes, $0=$ no $)$ & $0 \cdot 46$ & $0 \cdot 41-0 \cdot 53$ & $<0 \cdot 001$ & $0 \cdot 70$ & $0 \cdot 61-0 \cdot 81$ & $<0 \cdot 001$ \\
\hline Divorced $(1=$ yes, $0=$ no $)$ & $2 \cdot 00$ & $1 \cdot 48-2 \cdot 68$ & $<0 \cdot 001$ & - & - & - \\
\hline Widowed $(1=$ yes, $0=$ no $)$ & 1.48 & $0 \cdot 89-2 \cdot 45$ & $0 \cdot 134$ & - & - & - \\
\hline \multicolumn{7}{|l|}{ Age $($ ref. $<30)$} \\
\hline $30-39(1=$ yes, $0=$ no $)$ & $0 \cdot 90$ & $0 \cdot 80-1 \cdot 01$ & $0 \cdot 070$ & - & - & - \\
\hline $40-49(1=$ yes, $0=$ no $)$ & 0.79 & $0 \cdot 65-0 \cdot 95$ & $0 \cdot 013$ & - & - & - \\
\hline$\geqslant 50(1=$ yes, $0=$ no $)$ & 0.52 & $0 \cdot 29-0 \cdot 94$ & 0.029 & - & - & - \\
\hline \multicolumn{7}{|l|}{ Ethnicity $($ ref. $=$ Han $)$} \\
\hline Yi $(1=$ yes, $0=$ no $)$ & $0 \cdot 41$ & $0 \cdot 35-0 \cdot 47$ & $<0.001$ & - & - & - \\
\hline Other $(1=$ yes, $0=$ no $)$ & $2 \cdot 04$ & $1 \cdot 12-3 \cdot 73$ & $0 \cdot 020$ & - & - & - \\
\hline \multicolumn{7}{|l|}{ Socioeconomic factors } \\
\hline \multicolumn{7}{|c|}{$\begin{array}{l}\text { Employment (ref. = other, e.g. factory worker, government } \\
\text { employee, etc.) }\end{array}$} \\
\hline Farming $(1=$ yes, $0=$ no $)$ & $0 \cdot 44$ & $0 \cdot 38-0 \cdot 50$ & $<0 \cdot 001$ & - & - & - \\
\hline Unemployed $(1=$ yes, $0=$ no $)$ & $2 \cdot 64$ & $2 \cdot 26-3.08$ & $<0 \cdot 001$ & $1 \cdot 60$ & $1 \cdot 33-1.91$ & $<0 \cdot 001$ \\
\hline Service sector $(1=$ yes, $0=$ no $)$ & 1.74 & $1 \cdot 30-2 \cdot 35$ & $<0 \cdot 001$ & 1.73 & $1 \cdot 25-2 \cdot 39$ & $<0 \cdot 01$ \\
\hline \multicolumn{7}{|l|}{ Educational attainment (ref. $=$ no school) } \\
\hline Primary school & $1 \cdot 28$ & $1 \cdot 14-1 \cdot 44$ & $<0 \cdot 001$ & - & - & - \\
\hline Junior high school & $1 \cdot 64$ & $1 \cdot 43-1.87$ & $<0 \cdot 001$ & - & - & - \\
\hline Senior high school or above $(1=$ yes, $0=$ no $)$ & $1 \cdot 22$ & $1 \cdot 01-1 \cdot 48$ & 0.039 & $1 \cdot 28$ & $1.03-1.59$ & $<0.05$ \\
\hline
\end{tabular}

OR, Odds ratio; aOR, adjusted odds ratio; $\mathrm{CI}$, confidence interval.

factor, the spatial regression model can achieve many local ORs. The minimum, medium and maximum presented in Table 3 were the lowest local ORs, the median local ORs and the highest local ORs among these local ORs, respectively. Of drug-use behaviours, IDU was significantly $(P<0 \cdot 001)$ positively associated with $\mathrm{HCV}$ infection for all study individuals (Fig. 1), and drug rehabilitation was significantly $(P<0.05)$ positively related to $\mathrm{HCV}$ infection for $94.4 \%$ of study individuals in $94.5 \%$ of townships (Fig. 1).

Of demographic factors, being married was significantly $(P<0.05)$ negatively associated with HCV infection for $92 \cdot 8 \%$ of individuals compared to those who were single in $81.0 \%$ of townships; these townships were mainly distributed in the northeastern counties (Fig. 2). Yi ethnicity was significantly
$(P<0.05)$ negatively related to $\mathrm{HCV}$ infection for $71.7 \%$ of individuals compared to Han ethnicity in $62 \%$ of townships; these townships were mainly distributed in the southeastern counties (Fig. 2). Being female was significantly $(P<0.05)$ positively associated with HCV infection only in $11.2 \%$ of townships, located mainly in counties $\mathrm{E}$ and $\mathrm{F}$.

For socioeconomic factors, working in the service sector and unemployment (relative to factory workers and governmental employees) were significantly $(P<0.05)$ positively associated with $\mathrm{HCV}$ infection for only $5.8 \%$ of individuals in $14.3 \%$ of townships and $3.0 \%$ of individuals in $8.1 \%$ of townships, respectively; these townships are located mainly in the southern counties (Fig. 3). Senior high-school education or above (relative to no school) was significantly $(P<0 \cdot 05)$ positively associated with $\mathrm{HCV}$ infection 
Table 3. The local association of HCV infection and risk factors from the geographically weighted logistic regression model

\begin{tabular}{|c|c|c|c|c|c|c|c|c|}
\hline \multirow[b]{3}{*}{ Study variable } & \multirow{2}{*}{\multicolumn{2}{|c|}{ Minimum }} & \multirow{2}{*}{\multicolumn{2}{|c|}{ Medium }} & \multirow{2}{*}{\multicolumn{2}{|c|}{ Maximum }} & \multicolumn{2}{|c|}{ Significant $(\%)$} \\
\hline & & & & & & & \multirow{2}{*}{$\begin{array}{l}\text { Increased } \\
\text { risk }\end{array}$} & \multirow{2}{*}{$\begin{array}{l}\text { Decreased } \\
\text { risk }\end{array}$} \\
\hline & $B$ & OR & $B$ & OR & $B$ & OR & & \\
\hline Constant & $-2 \cdot 79$ & $0 \cdot 06$ & $-0 \cdot 97$ & $0 \cdot 38$ & $-0 \cdot 63$ & $0 \cdot 53$ & $0 \cdot 0$ & $99 \cdot 5$ \\
\hline \multicolumn{9}{|l|}{ Drug-use behaviours } \\
\hline Injection history $(1=$ yes, $0=$ no $)$ & $0 \cdot 79$ & $2 \cdot 21$ & $1 \cdot 02$ & $2 \cdot 77$ & $1 \cdot 46$ & $4 \cdot 29$ & $100 \cdot 0$ & $0 \cdot 0$ \\
\hline Sharing syringes $(1=$ yes, $0=$ no $)$ & $-0 \cdot 14$ & $0 \cdot 87$ & $0 \cdot 02$ & $1 \cdot 02$ & $0 \cdot 31$ & $1 \cdot 36$ & $0 \cdot 5$ & $0 \cdot 0$ \\
\hline Drug rehabilitation $(1=$ yes, $0=$ no $)$ & $0 \cdot 02$ & $1 \cdot 00$ & $0 \cdot 58$ & $1 \cdot 79$ & $1 \cdot 17$ & $3 \cdot 22$ & $94 \cdot 5$ & $0 \cdot 0$ \\
\hline \multicolumn{9}{|l|}{ Demographic factors } \\
\hline \multicolumn{9}{|l|}{ Marital status (ref. = single) } \\
\hline Married $(1=$ yes, $0=$ no $)$ & $-0 \cdot 49$ & $0 \cdot 61$ & $-0 \cdot 36$ & $0 \cdot 70$ & $0 \cdot 31$ & $1 \cdot 36$ & $0 \cdot 0$ & $81 \cdot 0$ \\
\hline Gender $(1=$ males, $0=$ females $)$ & $-1 \cdot 06$ & $0 \cdot 35$ & $-0 \cdot 11$ & $0 \cdot 90$ & $0 \cdot 04$ & $1 \cdot 04$ & $0 \cdot 0$ & $11 \cdot 2$ \\
\hline \multicolumn{9}{|l|}{ Ethnicity (ref. = Han) } \\
\hline Yi $(1=$ yes, $0=$ no $)$ & $-0 \cdot 64$ & $0 \cdot 53$ & $-0 \cdot 32$ & $0 \cdot 73$ & $0 \cdot 28$ & $1 \cdot 32$ & $0 \cdot 0$ & $62 \cdot 0$ \\
\hline Other $(1=$ yes, $0=$ no $)$ & $-0 \cdot 44$ & $0 \cdot 64$ & $0 \cdot 40$ & $1 \cdot 49$ & $3 \cdot 45$ & $31 \cdot 50$ & $0 \cdot 8$ & $0 \cdot 0$ \\
\hline \multicolumn{9}{|l|}{ Socioeconomic factors } \\
\hline \multicolumn{9}{|l|}{$\begin{array}{l}\text { Employment (ref. = other, e.g. factory worker, } \\
\text { government employee, etc.) }\end{array}$} \\
\hline $\operatorname{Farmer}(1=$ yes, $0=$ no $)$ & $-0 \cdot 56$ & $0 \cdot 57$ & $-0 \cdot 20$ & $0 \cdot 82$ & $0 \cdot 47$ & $1 \cdot 60$ & $0 \cdot 0$ & $3 \cdot 4$ \\
\hline Service sector $(1=$ yes, $0=$ no $)$ & $-0 \cdot 26$ & $0 \cdot 76$ & $0 \cdot 30$ & $1 \cdot 35$ & $2 \cdot 13$ & $8 \cdot 39$ & $14 \cdot 3$ & $0 \cdot 0$ \\
\hline Unemployed $(1=$ yes, $0=$ no $)$ & $-0 \cdot 11$ & $0 \cdot 90$ & $0 \cdot 23$ & $1 \cdot 26$ & $1 \cdot 56$ & $4 \cdot 76$ & $8 \cdot 1$ & $0 \cdot 0$ \\
\hline \multicolumn{9}{|l|}{ Educational attainment $($ ref. $=$ no school $)$} \\
\hline Primary school $(1=$ yes, $0=$ no $)$ & $-0 \cdot 18$ & $0 \cdot 84$ & $-0 \cdot 05$ & $0 \cdot 95$ & $0 \cdot 80$ & $2 \cdot 23$ & $5 \cdot 7$ & $0 \cdot 0$ \\
\hline Junior high school $(1=$ yes, $0=$ no $)$ & $-0 \cdot 30$ & $0 \cdot 74$ & $-0 \cdot 12$ & $0 \cdot 89$ & $0 \cdot 75$ & $2 \cdot 12$ & $1 \cdot 3$ & $0 \cdot 0$ \\
\hline Senior high school or above $(1=$ yes, $0=$ no $)$ & $0 \cdot 98$ & $0 \cdot 38$ & $0 \cdot 34$ & $1 \cdot 40$ & $0 \cdot 99$ & $2 \cdot 69$ & $55 \cdot 2$ & $0 \cdot 0$ \\
\hline
\end{tabular}

OR, Odds ratio.
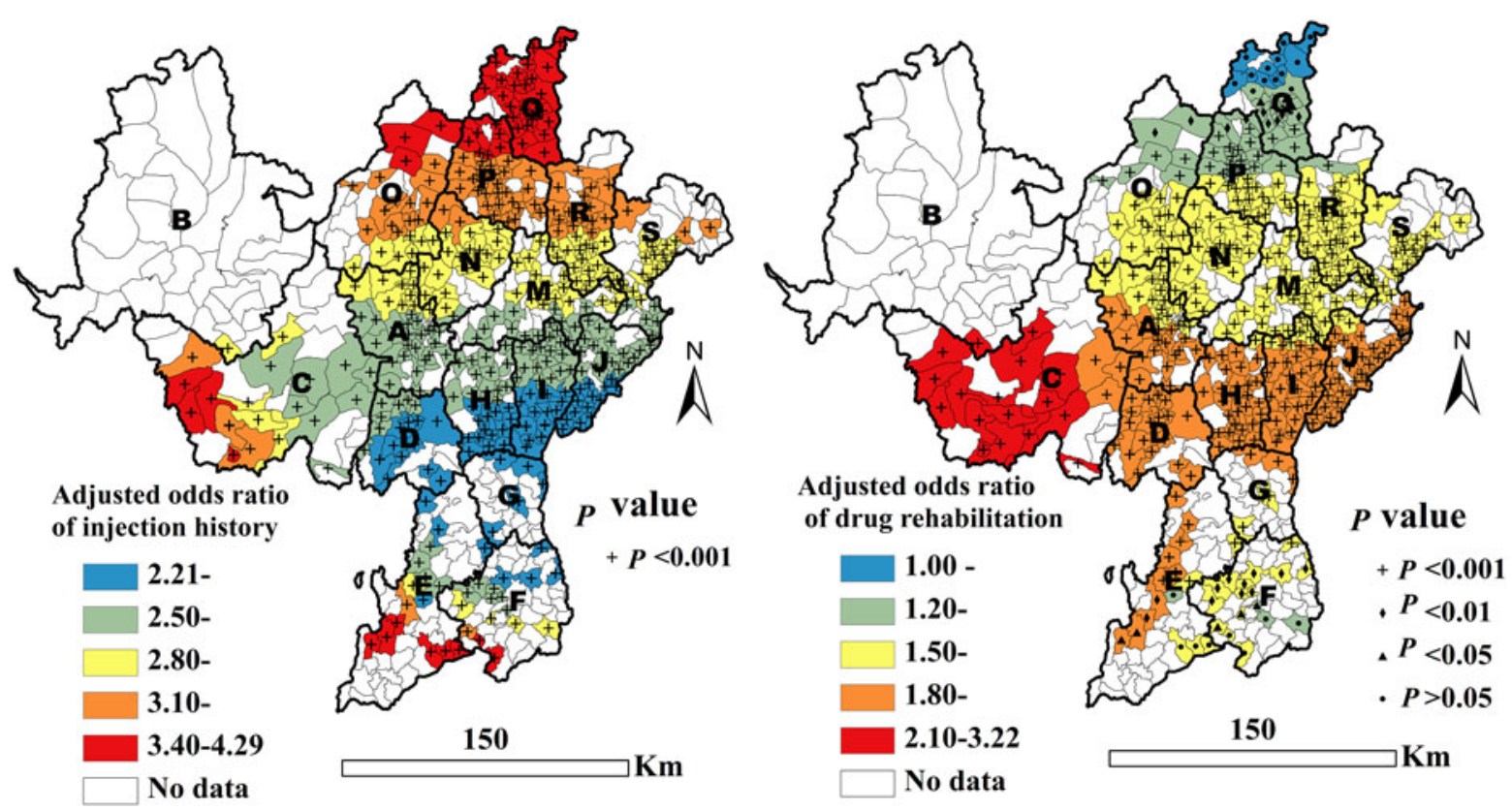

Fig. 1. Geographical distribution of adjusted odds ratios of injection history and drug rehabilitation history associated with HCV infection from the geographically weighted logistic regression model. 

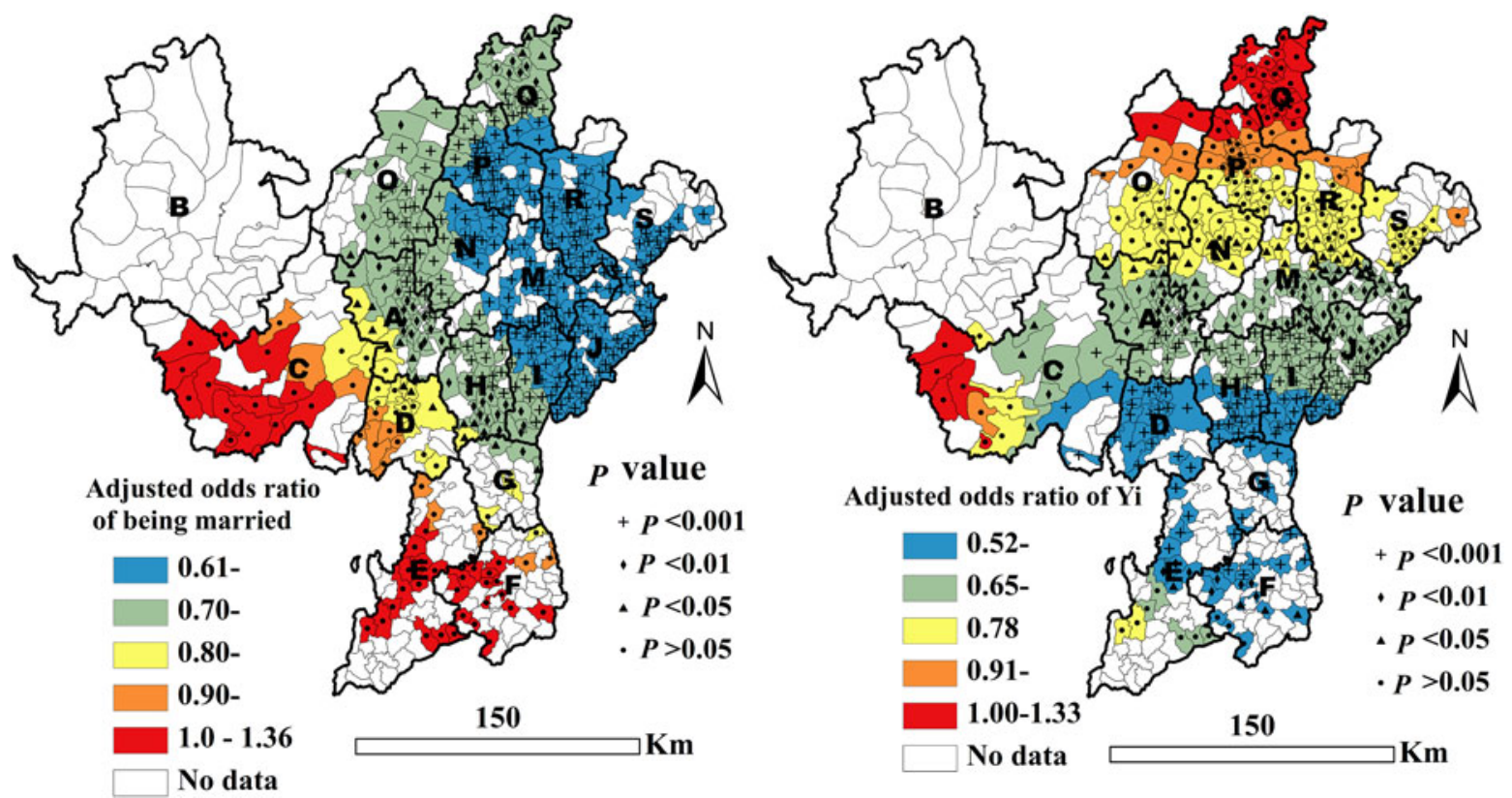

Fig. 2. Geographical distributions of adjusted odds ratios of being married and Yi ethnicity associated with HCV infection from the geographically weighted logistic regression model.
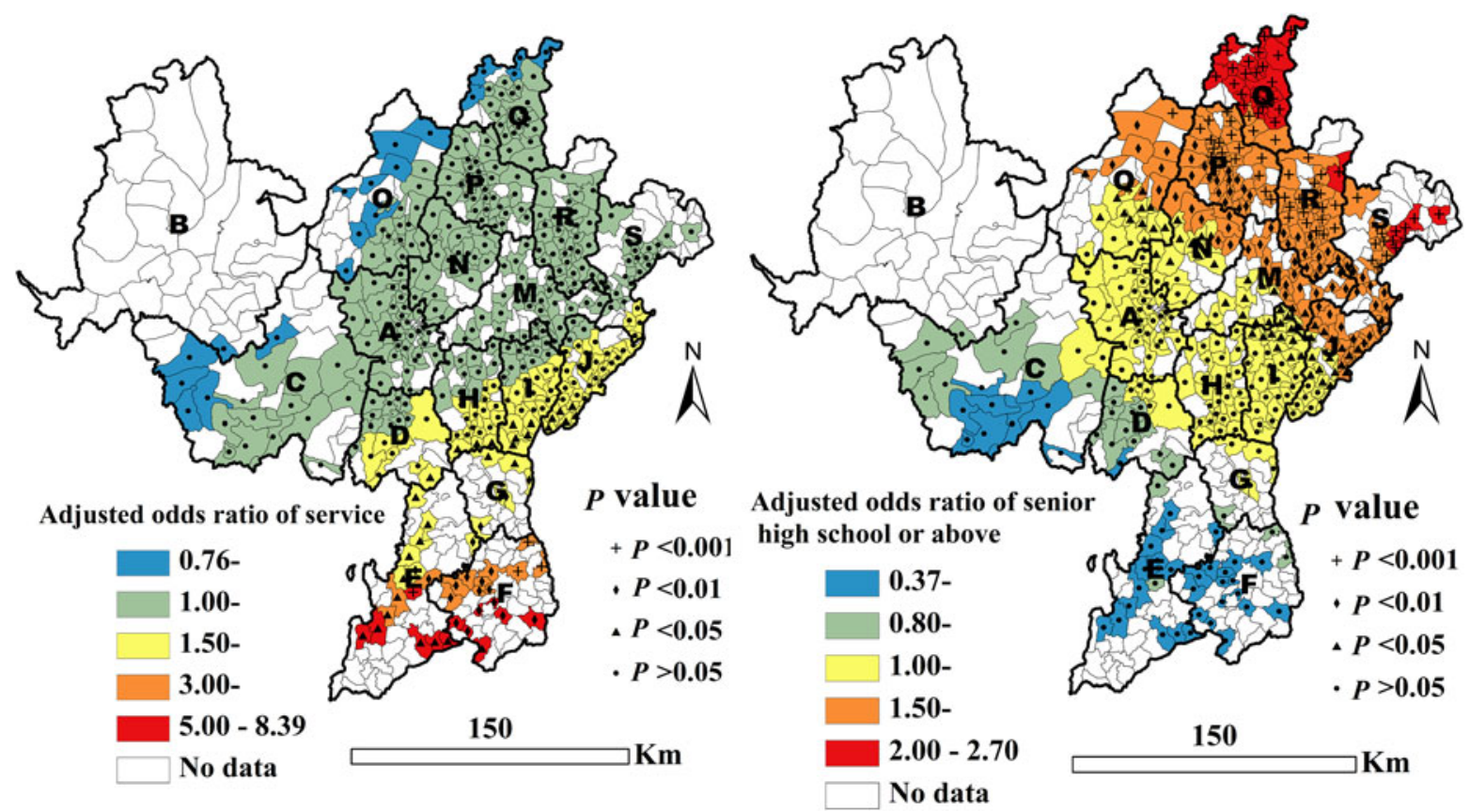

Fig. 3. Geographical distributions of adjusted odds ratios of HCV infection for service sector and senior high-school education or above from the geographically weighted logistic regression model.

for $57 \cdot 1 \%$ of individuals in $55 \cdot 2 \%$ of townships located in the northeastern counties (Fig. 3).

\section{DISCUSSION}

The non-spatial and the spatial analyses agreed on the role of IDU as a global (i.e. in the whole Yi Prefecture rather than in a specific township or county) high-risk factor for $\mathrm{HCV}$ infection, consistent with previous findings $[3,5,6,13,18]$. Both models also suggested that sharing syringes might be not an independent predictor of $\mathrm{HCV}$ infection in this study population, in accordance with previous studies [3, 19]. It seemed that the most likely factor affecting the significance 
of needle-sharing as a risk factor for $\mathrm{HCV}$ might be the prevalence of $\mathrm{HCV}$ in a given area. Some studies showed that sharing of injection paraphernalia (e.g. cookers, cotton) other than syringes may be an important cause of $\mathrm{HCV}$ transmission, and responsible for some proportion of new HCV infections [19-21]. These might partly explain why sharing syringes were not associated with the prevalence of $\mathrm{HCV}$ infection in half of the observed townships of the $\mathrm{Yi}$ Autonomous Prefecture in our previous study [13]. Interestingly, drug rehabilitation appeared to be a risk factor in both non-spatial and spatial analyses, confirming previous findings $[13,22,23]$. One plausible explanation for this is that the detoxification programmes might increase the frequency of the sharing use of drug injection paraphernalia (cookers, cotton, rinse water, drug solutions) [24]. However, such speculation requires further studies to confirm.

The GWLR model revealed the geographical variations of some risk factors associated with $\mathrm{HCV}$ infection which cannot be detected by the non-spatial logistic model. For example, the non-spatial logistic regression analysis suggested that being married was negatively associated with $\mathrm{HCV}$ infection, consistent with some studies [25, 26]. However, other studies suggested that marriage could be a risk factor for, or not related to, $\mathrm{HCV}$ infection [6, 9 27]. The spatial model showed that being married was negatively related to $\mathrm{HCV}$ infection for individuals primarily of Yi ethnicity living in the northeastern counties [10], but it was not significantly associated with $\mathrm{HCV}$ infection in southern counties where the majority of residents are of Han ethnicity (Fig. 2) [10]. This geographical variation of marital status associated with $\mathrm{HCV}$ infection might be related to the distribution of ethnicity. Whether the effect of marital status depends on ethnicity or culture needs future investigation. Examples of conflicting conclusions in previous studies that are possibly explained by spatial heterogeneity are also seen for the effects of ethnicity $[3,28]$ and gender $[3,5,8,9]$.

The non-spatial analysis indicated that senior highschool education or above was an independent risk factor for $\mathrm{HCV}$ infection, and the spatial analysis also showed that drug users with senior high-school education or above were more likely to be infected with HCV than those with no school in the northeastern counties of the Yi Autonomous Prefecture. These findings indicated that drug users with senior high-school education or above might be the priority population for intervention, especially in the north- eastern counties of the Yi Autonomous Prefecture, like $\mathrm{P}, \mathrm{Q}$ and $\mathrm{R}$ counties where drug users had high HCV infection prevalence [10].

Our findings have some important implications. First, geographical variations of risk factors associated with $\mathrm{HCV}$ infection might provide some guidance for tailoring site-specific intervention strategies to better control or prevent $\mathrm{HCV}$ transmission with limited resources. For example, drug users who are single and live in the northeastern counties, where marriage was negatively related to $\mathrm{HCV}$ infection, could be prioritized for intervention. Second, it is necessary to conduct health education in IDUs, making them aware of the potential risk of sharing injection paraphernalia in HCV transmission. Third, spatial correlation and heterogeneity should not be ignored in future studies of risk factors for $\mathrm{HCV}$ infection.

This study had several limitations. First, it is difficult to confirm whether patients of the methadone clinics are truly representative of the overall population of drug users. There was, however, a study reporting that the HIV prevalence in patients attending methadone clinics is not significantly different from that in drug users who do not attend methadone clinics [5], and the prevalence of HIV and HCV infections were significantly correlated across townships in the study area [10]. Second, the information regarding sexual behaviours was not available, and therefore we were unable to estimate or control for the effects of sexual behaviours on HCV infection. However, homosexuality (especially gay men) was rarely found in this study population, and an aggregate analysis indicated that there is no increased risk of sexual transmission of $\mathrm{HCV}$ in heterosexual couples in regular relationships [29]. The association of $\mathrm{HCV}$ infection with IDU may be confounded by increased number of multiple sexual partners with increased likelihood of IDU; however, the significant geographical variation of IDU in the association with $\mathrm{HCV}$ infection was not found in our study. Third, the interactions between variables were not analysed in this study because the spatial model cannot currently analyse the interaction. Finally, assigning the same coordinates to everyone in a township might be increase multicollinearity and reduce variance; however, an average of 13.3 patients per township has little impact on both multicollinearity and variance. For example, for injection drug history, the aOR $(95 \%$ CI $2.65-$ 3.48 ) from the non-spatial model is also very close to the aOR $(95 \%$ CI $2 \cdot 21-4 \cdot 29)$ from the spatial model. 


\section{CONCLUSION}

The geographical variations of some factors like marital status and educational attainment associated with $\mathrm{HCV}$ infection were found in drug users in this study area. These geographical variations of risk factors associated with $\mathrm{HCV}$ infection might provide some guidance for tailoring site-specific intervention strategies to better control or prevent HCV transmission in areas with limited resources. Spatial correlation and heterogeneity should not be ignored in future studies of risk factors for HCV infection.

\section{ACKNOWLEDGEMENTS}

This work was supported by funding from the Shanghai Leading Academic Discipline Project (Project no. B118) in the analysis and interpretation of data.

\section{DECLARATION OF INTEREST}

None.

\section{REFERENCES}

1. Kim AY, et al. An epidemiologic update on hepatitis $C$ infection in persons living with or at risk of HIV infection. Journal of Infection Disease 2013; 207: S1-6.

2. Shepard CW, et al. Global epidemiology of hepatitis C virus infection. Lancet Infectious Diseases 2005; 5: $558-567$.

3. Xia X, et al. Epidemiology of hepatitis $\mathrm{C}$ virus infection among injection drug users in China: systematic review and meta-analysis. Public Health 2008; 122: 990-1003.

4. McCarthy JJ, Flynn N. Hepatitis $C$ in methadone maintenance patients: prevalence and public policy implications. Journal of Addiction Disease 2001; 20: 19-31.

5. Zhuang X, et al. Risk factors associated with $\mathrm{HIV} / \mathrm{HCV}$ infection among entrants in methadone maintenance treatment clinics in China: a systematic review and meta-analysis. Drug and Alcohol Dependence 2012; 126: 286-295.

6. Paez Jimenez A, et al. Injection drug use is a risk factor for HCV infection in urban Egypt. PLoS ONE 2009; 4: e7193.

7. Alter MJ, et al. The prevalence of hepatitis $C$ virus infection in the United States, 1988 through 1994. New England Journal of Medicine 1999; 341: 556-562.

8. Cavlek TV, et al. Hepatitis C virus antibody status, sociodemographic characteristics, and risk behaviour among injecting drug users in Croatia. Central European Journal of Public Health 2011; 19: 26-29.

9. Dursun M, et al. Prevalence of Hepatitis $\mathrm{C}$ in adults in the south-eastern region of Anatolia: a communitybased study. Hepatology Reseach 2004; 29: 75-80.
10. Zhou YB, et al. The geographic distribution patterns of HIV-, HCV- and co-infections among drug users in a national methadone maintenance treatment program in Southwest China. BMC infectious Diseases 2014; 14: 134 .

11. Weidmann C, et al. A spatial regression analysis of German community characteristics associated with voluntary non-remunerated blood donor rates. Vox Sanguinis 2012; 102: 47-54.

12. Zhou YB, et al. Geographical variations in risk factors associated with HIV infection among drug users in a prefecture in Southwest China. Infectious Diseases of Poverty 2015; 4: 38.

13. Zhou YB, et al. HIV-, HCV-, and co-infections and associated risk factors among drug users in southwestern China: a township-level ecological study incorporating spatial regression. PLOS ONE 2014; 9: e93157.

14. Yin W, et al. Scaling up the national methadone maintenance treatment program in China: achievements and challenges. International Journal of Epidemiology 2010; 39: 29-37.

15. Du WJ, et al. Socio-demographic and clinical characteristics of 3129 heroin users in the first methadone maintenance treatment clinic in China. Drug and Alcohol Dependence 2008; 94: 158-164.

16. Pang L, et al. Effectiveness of first eight methadone maintenance treatment clinics in China. AIDS 2007; 21: S103-107.

17. Yang TC, Matthews SA. Understanding the nonstationary associations between distrust of the health care system, health conditions, and self-rated health in the elderly: a geographically weighted regression approach. Health Place 2012; 18: 576-585.

18. Champion JK, et al. Incidence of hepatitis $C$ virus infection and associated risk factors among Scottish prison inmates: a cohort study. American Journal of Epidemiology 2004; 159: 514-519.

19. Thorpe LE, et al. Risk of hepatitis C virus infection among young adult injection drug users who share injection equipment. American Journal of Epidemiology 2002; 155: 645-653.

20. Hagan $\mathbf{H}$, et al. Sharing of drug preparation equipment as a risk factor for hepatitis C. American Journal of Public Health 2001; 91: 42-46.

21. Villano SA, et al. Incidence and risk factors for hepatitis $\mathrm{C}$ among injection drug users in Baltimore, Maryland. Journal of Clinical Microbiology 1997; 35: 3274-3277.

22. Yen YF, et al. Prevalences and associated risk factors of $\mathrm{HCV} / \mathrm{HIV}$ co-infection and HCV mono-infection among injecting drug users in a methadone maintenance treatment program in Taipei, Taiwan. BMC Public Health 2012; 12: 1066.

23. Backmund M, et al. Hepatitis $\mathrm{C}$ virus infection in injection drug users in Bavaria: risk factors for seropositivity. European Journal of Epidemiology 2003; 18: 563-568.

24. Chen HT, et al. Correlations between compulsory drug abstinence treatments and HIV risk behaviors among 
injection drug users in a border city of South China. AIDS Education Prevention 2013; 25: 336-348.

25. Bao YP, et al. Prevalence and correlates of HIV and HCV infection among amphetamine-type stimulant users in 6 provinces in China. Journal of Acquired Immune Deficiency Syndromes 2012; 60: 438-446.

26. Kassaian N, et al. Hepatitis C Virus and associated risk factors among prison inmates with history of drug injection in Isfahan, Iran. International Journal of Prevention Medicine 2012; 3: S156-161.
27. Abdel-Aziz F, et al. Hepatitis C virus (HCV) infection in a community in the Nile Delta: population description and HCV prevalence. Hepatology 2000; 32: 111-115.

28. Lelutiu-Weinberger C, et al. A meta-analysis of the hepatitis $\mathrm{C}$ virus distribution in diverse racial/ethnic drug injector groups. Social Science \& Medicine 2009; 68: $579-590$.

29. Tohme RA, Holmberg SD. Is sexual contact a major mode of hepatitis $\mathrm{C}$ virus transmission? Hepatology 2010; 52: 1497-1505. 